\title{
Renal Stone Disease: A Commentary on the Nature and Significance of Randall's Plaque
}

Commentary in response to a minireview by Johri et al. [Nephron Clin Pract 2010;116:159-171]

\author{
A.P. Evan ${ }^{a} \quad$ R.J. Unwin ${ }^{b} \quad$ J.C. Williams, Jr. ${ }^{a}$ \\ ${ }^{a}$ Indiana University School of Medicine, Indianapolis, Ind., USA; ${ }^{\mathrm{U}}$ UCL Medical School, University College London, \\ London, UK
}

In this short follow-up commentary to the recent minireview on renal stone disease by Johri et al. [1], we seek to clarify one aspect of their review that is covered only briefly: current theories of kidney stone formation, including a physicochemical pathway driven by the supersaturation level of dissolved salts in the urine, intratubular crystal adhesion [2], and the Randall's plaque theory for calcium oxalate kidney stone formation and growth $[3,4]$. Much confusion exists in the literature regarding these theories; in particular it is often assumed that Randall's plaques are connected in some way with adhesion of crystals to tubular epithelial cells. However, Randall proposed no such adhesion of crystals in his original theory, and recent data collected in human stone formers have supported Randall's ideas. Thus, we now need to think of human stone formation in more than one category: The formation of some types of stones clearly involves the adhesion of crystals to the luminal surface of renal tubules, but the formation of stones on Randall's plaques does not involve crystal adhesion to epithelial cells. Finally, it may be that some stones form in the absence of Randall's plaques and also without crystal adhesion as an essential mechanism of stone formation.

\section{KARGER

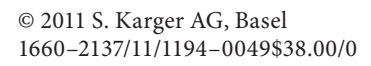

To better understand these three main potential pathways for stone formation [5], we have produced an illustration (fig. 1) that depicts the site of initial mineralization along the nephron/renal pelvis, and the final location of the developing stone for each pathway. The three pathways are labeled: 'free-particle' stone formation, stone formation on a plug (sometimes referred to as the 'fixed-particle' model), and Randall's plaque. In this short paper we will confine our discussion to the Randall's plaque hypothesis and touch only briefly on the other two theories. To give a historical perspective to Randall's plaque hypothesis, we will begin by reviewing his original observations and then link them to our own more recent findings.

\section{Observations Made by Randall}

It was Randall who reasoned from clinical observations in his own clinical practice of stone disease that: (1) there must be an initiating lesion that precedes the formation of a primary renal calculus, and (2) that such an initiating lesion was to be looked for on the renal papilla. It was from these seemingly self-evident facts as a guide 


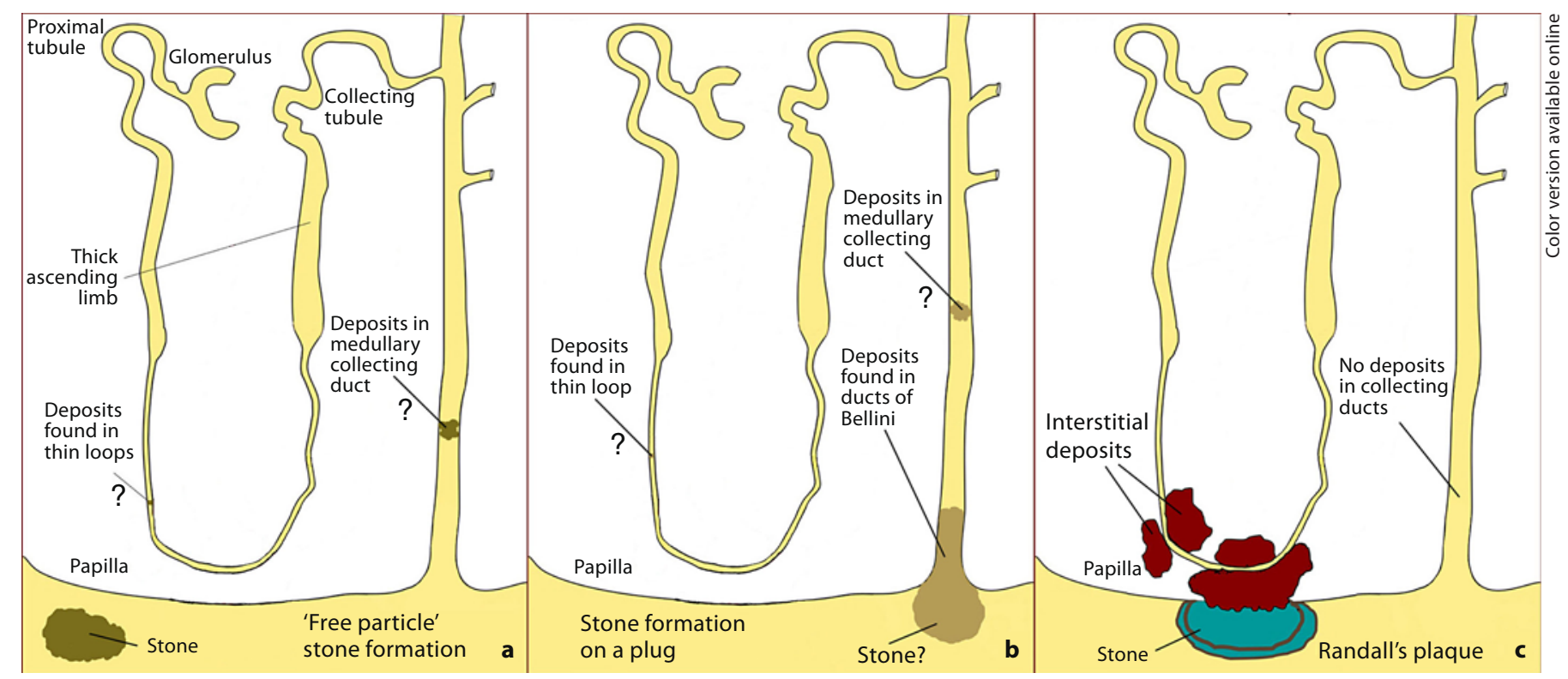

Fig. 1. Models of renal stone formation (see text for details).

that Randall first studied 265 naturally voided stones for the presence of a mural attachment site. In 106 , or $40 \%$, of the 265 stones he examined, he found a visible facet on the surface of the stone that was of a different color from the rest of the stone. In his mind this finding strongly supported his original hypothesis that an initiating lesion was required for stone formation. Therefore, Randall decided to obtain direct evidence to test his hypothesis by examining human kidneys, and particularly the renal papilla, for evidence of a mural attachment site. Using a hand lens, Randall [4] examined 1,154 pairs of kidneys obtained at autopsy and found calcium deposits on the renal papilla in 227 (19.6\%) individuals, and a primary renal calculus in 65 of them. From his visual inspection, the papillary lesion appeared creamy colored and located beneath the urothelium. Histological examination of such a lesion site revealed deposits of calcium salts, termed Randall's plaque or papillary lesion type 1 , in the interstitial tissues of the papilla near segments of the nephron (fig. 1c). Chemical analysis of these deposits suggested the mineral composition to be calcium phosphate. No deposits were found in the nephron lumen as an intratubular plug, nor was there any evidence of inflammation.

Randall also discovered sites of black material (a small stone) overlying a region of interstitial plaque. In two cases, Randall was able to embed the stone-plaque complex and section the specimen for light microscope analysis. The stone (black material) was continuous with the inter- stitial plaque, with no evidence of a urothelial covering or barrier between the two mineral sites. Mineral analysis of the stone detected calcium oxalate, whereas the interstitial plaque material was composed of calcium phosphate. Thus, Randall viewed stone formation as beginning with the deposition of calcium phosphate in the interstitial tissues of the renal papilla; this lesion, though buried in the renal papilla, eventually loses its epithelial covering to become bathed in calyceal urine. By acting as a 'foreign body', the exposed plaque material becomes the nidus on which a different urinary salt can crystallize to form a new (surface) calculus (fig. 1c).

\section{Recent Observations on Randall's Plaque}

Recent studies, including endoscopic investigation and biopsy of stone-forming patients, have supported Randall's hypothesis as the basis for stones in some types of stone patient, specifically for the idiopathic calcium oxalate stone formers (ICSF). However, these studies have also shown that other kinds of stone disease are associated with intratubular plugging of collecting ducts, with or without the presence of Randall's plaque [6-14]. These investigations into the actual pathophysiology underlying stone disease in well-characterized patient groups suggest that 'stone disease' - implying as it does a single disorder - is perhaps a misnomer, and that there are several 
distinct pathologies resulting in the formation of urinary stones (although their total number is still not determined).

To date eight different stone-forming groups have been described: ICSF, brushite (hydrated calcium phosphate), intestinal bypass for obesity, cystinuria, distal renal tubular acidosis, ileostomy, small bowel resection, and hyperparathyroidism; an additional group of nonstone formers has also been examined [6-14]. It is the ICSF group, and only this group, that closely matches the observations of Randall [7]. To date, biopsies from 30 ICSF individuals have been reported using a variety of fixation techniques $[7,8]$. Digital endoscopic examination of the renal papillae of ICSF patients clearly show irregular whitish regions, usually near the papillary tip, on most, if not all, papillae; these are the deposits Randall observed with a hand lens and called papillary type 1 lesions. Light microscopic examination of biopsies obtained from these sites reveals suburothelial deposits (plaque) of varying amounts located strictly to the papillary interstitium and never in the tubular lumen. No evidence of cell injury or of an inflammatory reaction has been seen in any of these patients.

By examining regions with limited plaque versus regions of heavy plaque, deposits appear to originate in the basement membrane material of the thin loops of Henle, and then develop in, and spread along, the interstitial space, where they accumulate to form large islands of crystals that float in a sea of organic matrix material. The deposits within the basement membrane appear as single laminated spheres with a varying number of light (crystals) and dark (matrix) rings or layers - like the rings of a tree - that contain a variety of proteins (osteopontin, heavy chain of inter- $\alpha$-trypsin) $[15,16]$.

Like Randall, a recent study has reported on several small stones attached to sites of interstitial plaque and the stone material was successfully sampled intact, together with its underpinning of interstitial plaque material [17]. Electron microscopic analysis of these samples revealed that there is a continuum of crystalline material that extends from the interstitium to the actual stone, with a folded multilayered ribbon that forms an outer boundary between denuded plaque and the urinary space, due to a loss of urothelial cells that normally cover the interstitial tissues of the papilla. The ribbon consists of layers of crystal alternating with organic matrix. The innermost layer is of urinary origin and is covered by successive layers of crystals and matrix, until crystallization escapes from the matrix and proceeds to form a stone. Calcium phosphate in the ribbon is amorphous; successive layers over the rib- bon, which forms the base of the new stone, become biological apatite, while the stone first appears as calcium oxalate admixed with apatite, and eventually only calcium oxalate. These observations suggest that the original interstitial plaque exposed to urine was covered over with matrix molecules of urinary origin and crystals formed in it, driven by urine supersaturation (particularly that for calcium phosphate); matrix covered the new crystals, a ribbon of alternating matrix and crystal formed, and eventually crystallization escaped from the matrix modulation to form a stone.

These observations on interstitial plaque in ICSF patients lead to the hypothesis that in ICSF patients stones grow on interstitial plaque. To test this hypothesis, a study was designed to determine whether every attached stone is attached to plaque or if a stone is attached in such a manner that the underpinning cannot be seen [18]. Such a design was feasible because of the capabilities of the new flexible digital endoscope. A study of 9 ICSF patients found a total of 115 stones, 90 of which were attached; 81 of the 90 were determined to be attached to plaque. The final point estimate for the number of stones attached to plaque was 0.754 (95\% CI 0.575-0.933), with a corresponding $\mathrm{p}=0.013$, which allows us to conclude that growth on interstitial plaque appears to be a primary mechanism for stone formation in ICSF, the most common type of patient encountered in clinical practice.

\section{Intraluminal Deposits}

The second major histopathological pattern noted in kidney stone patients is intraluminal crystalline deposits along the distal nephron (i.e., inner medullary collecting ducts and ducts of Bellini) and, infrequently, in the thin loops of Henle (fig. 1b) [5-14]. Varying degrees of interstitial fibrosis and cell damage can be associated with plugged tubules. These mineral plugs are occasionally (about one per papilla) seen protruding from dilated openings of the ducts of Bellini, and in some instances have stone material growing from their distal ends. This histopathological pattern of tubular plugging and fibrosis has been reported in seven of the eight stone-forming groups listed earlier, and included the following: brushite, intestinal bypass surgery for obesity, cystinuria, small bowel resection, distal renal tubular acidosis, ileostomy, and hyperparathyroidism. In four of the seven stone-forming groups - intestinal bypass surgery for obesity, brushite, cystinuria and distal tubular acidosis - intraluminal plugging along with interstitial fibro- 
sis was the primary change noted, while in small bowel resection, ileostomy, and hyperparathyroidism there were also varying numbers of stones attached to Randall's plaque.

The amount and size of the intraluminal deposits varied by stone type [6], with intestinal bypass surgery for obesity and brushite stone former deposits occupying a minority of tissue volume: they were small in bypass patients, but individually large in brushite patients. Deposits were more numerous and space-filling in hyperparathyroidism and in ileostomy patients: the former group formed deposits of modest individual size, whereas the latter had very large individual deposits. In renal tubular acidosis, deposits were individually large and filled a large fraction of tissue volume. Interestingly, those patients with large, rather diffuse, papillary deposits also have nephrocalcinosis as seen on a CT scan. The mineral type of the tubular plugs was usually apatite, the exceptions being in the ducts of Bellini of cystinuric patients (cystine), ileostomy (sodium acid urate and ammonium acid urate), and distal tubular acidosis (primarily apatite with some calcium oxalate). In addition, patients with intestinal bypass surgery for obesity have apatite deposits filling the distal nephron, with an occasional mixture of calcium oxalate. Thus, the mineral analysis data suggest that at least two different processes are occurring: one resulting in apatite formation and the other generating deposits of varying type within the ducts of Bellini.

The histopathological pattern of intraluminal plugging described above is in keeping with the 'fixed-particle' theory proposed by Finlayson and Reid [19], and later developed by Kok and Khan [20] to include crystal agglomeration, resulting in renal tubular obstruction (fig. 1b). However, the primary question prompted by these data is: Do sites of intraluminal deposits lead to stone formation and, if so, how? To date, there are no studies that present experimental or human data that can answer this important question. Recent observations suggest that there might be two pathways for stone formation in some patients. First, the sites of protruding plugs from dilated ducts of Bellini may be a site of stone formation and growth (fig. 1b), and human studies have shown several examples of this process. However, we have observed only a small number of such events, so it is difficult to believe that this process leads to the formation of multiple stones per patient. The second pathway involving 'free-particle' formation of stones seems more likely (fig. 1c), and could lead to the multiple stones seen in intestinal bypass and cystinuric patients; although neither pathway has been as rigorously studied as the stones associated with Randall's plaque in ICSF patients.

In summary, the seminal observations of Randall have been confirmed in some groups of stone patients: idiopathic calcium oxalate stone formation involves no pathology of the renal tubules, neither tubular plugging nor inflammation of any kind; stones in these patients apparently form only on interstitial plaque at the papillary tip that becomes exposed to calyceal urine. Other kinds of stone formers, such as those with brushite stones or those with significant hyperoxaluria, clearly have collecting ducts that become plugged by mineral, and the long-term implications of these tubular obstructions for renal function are unknown. There are some kinds of stone formers in whom the urinary concretions may form within the calyceal or pelvic spaces, and without a specific connection to the renal tissue; however, the mechanisms by which this can occur, and whether or not this pathology is associated with damage to the kidney parenchyma, remain to be elucidated. Indeed, there is still much to learn and understand about renal stone formation; the more so, since renal stone disease is becoming an increasingly significant health and economic burden, and it is also emerging as an important cardiovascular risk factor in its own right.

\section{References}

1 Johri N, Cooper B, Roberson W, Choong S, Rickards D, Unwin R: An update and practical guide to renal stone management. Nephron Clin Pract 2010;116:159-171.

-2 Asselman M, Verhulst A, Van Balegooijen ES, Bangma CH, Verkoelen CF, De Broe ME: Hyaluronan is apically secreted and expressed by proliferating or regenerating renal tubular cells. Kidney Int 2005;68:7183.

73 Randall A: The origin and growth of renal calculi. Ann Surg 1937;105:1009-1027.
-4 Randall R: Papillary pathology as precursor of primary renal calculus. J Urol 1940;44: 580-589.

5 Coe FL, Evan AP, Worcester EM, Lingeman JE: Three pathways for human kidney stone formation. Urol Res 2010;38:147-160.

6 Coe FL, Evan AP, Lingeman JE, Worcester EM: Plaque and deposits in nine human stone diseases. Urol Res 2010;38:263-269.
Evan AP, Lingeman JE, Coe FL, Parks JH, Bledsoe SM, Shao Y, Sommer A, Paterson R, Kuo R, Grynpas M: Randall plaque of patients with nephrolithiasis begins in basement membranes of thin loops of Henle. J Clin Invest 2003;111:607-616.

8 Evan AP, Coe FL, Gillen D, Lingeman JE, Bledsoe S, Worcester EM: Renal intraluminal crystals and hyaluronan staining occur in stone formers with bypass surgery but not with idiopathic calcium oxalate stones. Anat Rec 2008;291:325-334. 
9 Evan AP, Lingeman JE, Coe FL, Shao Y, Parks JH, Bledsoe SB, Sommer AJ, Paterson RJ, Kuo RL, Kim S, Grynpas M: Crystal associated nephropathy in patients with brushite nephrolithiasis. Kidney Int 2005;67:576-591.

-10 Evan AP, Coe FL, Lingeman JE, Shao Y, Matlaga BR, Kim S., Bledsoe SB, Sommer AJ, Grynpas M, Philips CL, Worcester EM: Renal crystal deposits and histopathology of the kidney in cystinuria. Kidney Int 2006;69: 2227-2235.

- 11 Evan AP, Lingeman JE, Coe F, Shao Y, Miller N, Matlaga B, Phillips C, Sommer A, Worcester EM: Renal histopathology of stone-forming patients with distal renal tubular acidosis. Kidney Int 2007;71:795-801.

-12 Evan AP, Lingeman JE, Coe FL, Miller N, Bledsoe S, Sommer A, Williams J, Shao Y, Worcester E: Histopathology and surgical anatomy of patients with primary hyperparathyroidism and calcium phosphate stones. Kidney Int 2008;74:223-229.
13 Evan AP, Lingeman JE, Coe FL, Bledsoe S, Sommer A, Williams J, Krambeck A, Worcester E: Divergence between intratubular deposits and urine and stone composition in patients with ileostomy. Kidney Int 2009; 67:1081-1088.

14 Evan AP, Lingeman JE, Worcester EM, Bledsoe SB, Sommer AJ, Williams JC, Krambeck A, Philips C, Coe FL: Renal histopathology and crystal deposits in patients with small bowel resection and calcium oxalate stone disease. Kidney Int 2010;78:310-317.

15 Evan AP, Coe FL, Rittling SR, Bledsoe SB, Shao Y, Worcester EM, Lingeman JE: Apatite plaque particles in inner medulla of kidneys of $\mathrm{CaOx}$ stone formers: osteopontin localization. Kidney Int 2005;68:145-154.
6 Evan AP, Bledsoe S, Worcester EM, Coe FL, Lingeman JE, Bergsland KJ: Renal inter- $\alpha$ trypsin inhibitor heavy chain 3 increase in calcium oxalate stone-forming patients. Kidney Int 2007;72:1503-1511.

-17 Evan AP, Coe FL, Lingeman JE, Shao Y, Sommer AJ, Bledsoe SB, Anderson JC, Worcester EM: Mechanism of formation of human calcium oxalate renal stones on Randall's plaque. Anat Rec 2007;290:1315-1323.

18 Miller NL, Gillen DL, Williams JC, Evan AP, Bledsoe SB, Coe FL, Worcester EM, Matlaga BR, Munch LC, Lingeman JE: A formal test of the hypothesis that idiopathic calcium oxalate stones grow on Randall's plaque. BJU Int 2009; 103:966-971.

19 Finlayson B, Reid F: The expectation of free and fixed particles in urinary stone disease. Invest Urol 1978;15:442-448.

-20 Kok DJ, Khan SR: Calcium oxalate nephrolithiasis, a free or fixed particle disease. Kidney Int 1994;46:847-854. 